\title{
Machado de Assis, cem anos depois
}

\author{
Pedro Meira Monteiro
}

ano de 2008 deixa, em meio às inúmeras comemorações do centenário de morte de Machado de Assis, um rastro fecundo, cuja importância somente a posteridade poderá avaliar, em toda sua extensão e profundidade. Este número especial da Luso-Brazilian Review traz, já quase ao fim da celebração, seu próprio quinhão de luz para a compreensão do maior autor da literatura brasileira.

Os artigos aqui reunidos provêm, em boa parte, de alguns dos painéis que, na última reunião da American Portuguese Studies Association, ocorrida neste último ano em Yale University, tematizaram Machado de Assis. Evidentemente, trata-se de uma amostra incompleta daquilo que lá se apresentou e discutiu. É significativo, entretanto, que os textos aqui reunidos sejam encabeçados por um pequeno ensaio de Alfredo Bosi, composto durante esta que foi sua primeira viagem acadêmica aos Estados Unidos, quando, ainda em outubro de 2008, ele esteve em Princeton University, para depois, justamente, proferir a conferência machadiana que inaugurou o congresso da APSA em Yale. Creio que o sentido de sua contribuição à Luso-Brazilian Review seja claro: no momento em que o tema da "universalidade" retorna com força ao âmbito da crítica sobre Machado de Assis, um de seus maiores intérpretes vem somar sua voz à ampla discussão que se desenrola internacionalmente, em especial no circuito acadêmico norte-americano.

Pontuo a seguir o que me parecem ser os elementos centrais de cada um dos textos aqui reunidos.

O ensaio de Alfredo Bosi, "Rumo ao concreto: Brás Cubas em três versões", parte de considerações de um estudo anterior, em que se desenhavam as três principais tendências na análise do texto machadiano: a que privilegia a forma (análise "construtiva"), a que atenta especialmente para a dimensão existencial que dá tom à narrativa ("expressiva"), e a que explora a dimensão alegórica do texto e a tipificação de narradores e personagens ("representativa"). Valendo-se do espírito de um pensamento célebre de Pascal, segundo o qual "demasiada distância e demasiada proximidade impe- 
dem a vista", Bosi adverte para os limites de uma crítica sociologizante, ou historicizante, assim como para a insuficiência da crítica formalista. Ao postular a necessidade de recorrer aos três níveis de análise simultaneamente, o texto não esconde, contudo, certa simpatia pela dimensão existencial que tem em Augusto Meyer o seu grande crítico, e que leva sempre à inquirição do tom que permeia a obra. Por fim, a delicada questão da "universalidade" e do caráter "local" da prosa machadiana revela-se em toda sua potência: Machado, na leitura proposta, oscila entre a sátira com endereço claro e o humor que suspende todas as referências. O estilo caprichoso, que dá a tal prosa o seu conhecido sabor, deixa correr, no fundo, o fio do humor que a tudo desmancha: aí o nó machadiano, que o artigo fixa com delicadeza.

O estudo de Earl Fitz, "The Reception of Machado de Assis in the United States during the 1950 s and 1960s", compreende diversos momentos da recepção machadiana nos Estados Unidos, atentando ora para o contexto social ora para o contexto propriamente literário. A análise, clara e precisa, inicia-se com o ambiente relativamente eufórico da prosperidade econômica norte-americana no pós-guerra, que teria levado diversos leitores à recusa da amarga mensagem de Machado de Assis, num tempo em que, a despeito de algumas resenhas positivas, a compreensão das Memórias póstumas de Brás Cubas (Epitaph of a Small Winner) não escaparia àquela sensação que o julgamento de Dudley Fitts resume à perfeição: "No satirist, not even Swift, is less merciful". Em seguida, ao analisar o "Boom" dos anos sessenta, Fitz lança uma pergunta que avança pelo produtivo campo das hipóteses sobre a recepção: "What would Machado's reception in the United States have been if he had been marketed differently, or if he had been recognized immediately by his reviewers as a writer who had something important to say about [the] great issues of the time?” Ao fim, a análise recai sobre a recepção de Machado por John Barth, desde o júbilo do contato inicial até sua substituição por Borges, nesta que é uma significativa pequena galeria de grandes autores latino-americanos.

No artigo seguinte, "Uma vocação em busca de línguas: notas sobre as (não) traduções de Machado de Assis", Hélio de Seixas Guimarães, que tem também se destacado no estudo da recepção e circulação da obra machadiana, analisa documentos que revelam o desejo do escritor brasileiro em ver sua obra circular fora de seu país, e não apenas em português. Assim, percebemos a aguda consciência de Machado sobre a circulação das letras e sobre a literatura como negócio, no século XIX. Durante sua vida, acumulamse tentativas frustradas de ver sua obra circular em Portugal, de fazer-se traduzir ao alemão, e de ver as Memórias póstumas de Brás Cubas traduzidas ao francês. Entretanto, as únicas traduções de livros seus, que Machado viu, foram as de Memórias Póstumas de Brás Cubas e Esaú e Jacó, ambas publicadas em espanhol, no Uruguai e na Argentina. De resto, o escritor brasi- 
leiro terminou no mesmo "beco" em que "meteu vários de seus personagens ficcionais", incapazes muitas vezes de uma "comunicação com os homens", como provocativamente sugere Guimarães. A partir daí, o artigo nos permite inquirir o sentido da consciência sobre o fracasso da circulação da obra literária brasileira, o que teria levado Machado, por fim e porventura, a uma crescente tematização do livro, assim como da exigüidade e insignificância do leitor.

O artigo de Paul Dixon, "Machado de Assis, the 'Defunto Autor' and the Death of the Author", atenta também para a história da recepção de Machado de Assis, dentro e fora do Brasil, analisando-a porém em contraste à evolução da teoria literária no século XX, com o relativo desprestígio dos estudos que buscam a "intenção" e investem na instância autoral desprestígio que conecta o New Criticism à propalada "morte do autor", de tamanha repercussão e influência no quadro crítico contemporâneo. No plano da crítica machadiana, curiosamente, ao esvaziamento da instância autoral ("o livro é tudo") contrapõe-se um forte investimento na intencionalidade do autor, que une as análises de Roberto Schwarz e John Gledson, ambas aliás devedoras do pioneirismo de Helen Caldwell. Não menos curioso, do ponto de vista de Dixon, é o fato de que venham sobretudo de fora do Brasil, de Portugal e de uma parte da academia anglófona, as respostas mais fortes ao intencionalismo nos estudos machadianos. Respostas essas que re-investem na ambigüidade inerente ao texto de Machado, sinalizada, sempre, pela impossiblidade de verificação da culpa de Capitu. O leitor verá então que o artigo, para além de sua inegável qualidade analítica, termina, inadvertidamente ou não, por "make a case", defendendo e trazendo à luz toda uma vertente da crítica machadiana que floresce principalmente fora do Brasil, a partir de um ambiente acadêmico diverso, talvez pouco assombrado pelo tema da brasilidade do autor.

José Luiz Passos, em "O Mal e a Metamorfose em Machado de Assis", propõe uma iluminadora aproximação à questão moral que atravessa a obra machadiana, seguindo também hipóteses levantadas em estudo anterior. Tendo como principais focos Iaiá Garcia e Dom Casmurro, o artigo esclarece os momentos em que o sujeito ficcional se defronta com o desdobramento de seu próprio eu (algo a que Passos chamará "metamorfose"), sempre a partir da percepção fantástica da complexidade do Outro, que é também um sujeito capaz de desdobrar-se em máscaras sucessivas, reconhecendo-se e desconhecendo-se a si mesmo. Em pauta está o interminável confronto entre, de um lado, aquilo que o eu percebe ou constrói como seu próprio passado e, de outro, o seu presente, quando o enigma do Outro (projetado também ao passado do Outro) converte-se em um ingente desafio. Desafio, aliás, que abre ao sujeito, como criatura moral, a possibilidade de conceber o mal no outro, o que é já a marca da malícia em si. No fundo, a malícia caracteriza esse sujeito 
a um tempo cindido e atormentado, capaz da "divagação perquiridora" que o torna um personagem complexo e completo, uma pessoa, enfim.

Em linha algo paralela ao artigo anterior, Eliane Robert Moraes analisa, em "Um vasto prazer, quieto e profundo", o conto "A causa secreta", procurando desvendar o que seria o conteúdo sádico próprio à ação de um dos personagens que, na cena principal desenhada por Machado, delicia-se em torturar um rato. A multiplicação dos detalhes da tortura, o caráter metódico e espetacular do martírio a que se expõe a criatura, assim como o gozo diante dos limites que separam o corpo do Outro da morte, parecem aproximar o nosso autor de Sade. Daí, precisamente, a tirada de humor lacaniano que resume esse belo artigo: "Machado avec Sade?" Porém, a autora sugere uma diferença fundamental entre o Divino Marquês e o escritor brasileiro diferença que termina por iluminar a ficção machadiana, para muito além do conto analisado. É que, enquanto em Sade aquele limite diante da morte e do mal se multiplica até às raias do impensável, criando o cenário inverossímil das alcovas em que impera o deboche, em Machado a rotina e certa verossimilhança acompanham cada personagem, inclusive o mais sádico deles. Aí a "profundidade psicológica" própria à grande escrita realista do século XIX, que separa a peça brasileira de sua congênere setecentista. O "efeito de realidade" é diverso, e o que era espetáculo típico em Sade, em Machado de Assis converte-se em um plausível ritual interior ao sujeito, o qual, ainda que não freqüente o espaço reservado à perversão, não escapa da proximidade com o mal, tendo que haver-se com aquilo que, em termos próximos às teses de Foucault, se chamará a privatização do tormento.

O artigo seguinte, “'O espelho': superfície e corrosão”, de Alcides Villaça, recorda, em seu tecido finíssimo, alguns dos mais altos momentos da crítica machadiana, quando, na pena de Augusto Meyer, a duplicidade de Machado de Assis era trabalhada, reclamando atenção sucessiva à superfície e ao fundo daquilo que o texto oferece aos nossos olhos, isto é, a confusa matéria humana. A análise de "O espelho" empreendida por Villaça permite compreender como a própria estruturação da narrativa faz par à matéria narrada, já que tudo no conto se passa num entre-lugar que, ao fim, descobrimos ser o espaço que medeia entre as "duas almas" que o personagem principal (narrador ele mesmo) postula: a interior e a exterior. "Prazerosa exterioridade" e "inalienável interioridade crítica" são os dois pólos que machadiamente marcam a cadência de uma investigação que é da própria alma humana. Uma alma que, embora muitas vezes se acredite monádica, ameaça consumir-se e sumir no horizonte trágico de uma experiência extrema, quando Jacobina não tem mais ninguém, nem os escravos, a confirmar a importância de suas próprias marcas de excelência. (Como sugere o artigo, em certo ponto: “Quem somos, se ninguém nos vê?") Somos então levados a constatar que o ponto de chegada da análise machadiana é um materialismo quase impiedoso, que aponta para os limites do homem porque o 
toma por mais uma peça, apenas, no palco em que se combinam e se chocam as forças naturais. Contra o horizonte cáustico e cético dessa constatação final, Villaça lembra a reinterpretação rosiana do conto, que aponta para aquela transcendência que em Machado falta e em Guimarães Rosa sobra.

O artigo de Lúcia Granja, "Antes do livro, o jornal: 'Conto Alexandrino”,, continua a importante pesquisa com que, há vários anos, a autora vem cercando a obra de Machado de Assis, tomando em consideração a materialidade da produção literária, sua circulação e inserção num suporte específico, que em si mesmo tem sua história e que deve portanto ser analisado junto ao texto que os contemporâneos conhecemos isolado de suas condições originais de produção. $\mathrm{O}$ "Conto Alexandrino" ganha novo realce se atentamos para as notícias que o circundaram quando publicado, ou, no caso, as notícias que se veicularam nos jornais cariocas, pouco antes de sua redação. É o caso de uma reportagem de cuja inverossimilhança Machado irá burlar-se, ainda em crônica de 1878 , e que sugere que o autor que hoje apenas conhecemos por sua própria produção estava em constante conversa com o seu entorno "jornalístico". Assim também, o artigo de Granja traz à luz uma notícia no Jornal do Commercio, sobre os experimentos algo escabrosos de um médico da corte que buscava um antídoto ao veneno utilizado por certos indígenas nas pontas de suas flechas. A tortura animal, que fornece a matéria ficcional de Machado de Assis no "Conto Alexandrino" (e não só nele, como já terá notado o leitor), ali aparece nua e crua, com as cores e os tons com que a viam os leitores coevos. O motivo e a inspiração de Machado teriam sido, portanto, disparados ou condicionados pela notícia corriqueira, que na pena do escritor ganha novo sentido. A análise relembra e presentifica, justamente, esse disparo e essas condições, sem os quais a matéria literária não existiria - ao menos não a matéria que conhecemos hoje.

No último artigo, Luís Augusto Fischer e Lucia Serrano Pereira, que têm também se dedicado à obra machadiana nos últimos anos, conjugam suas pesquisas em "O dilema do polquista: a formação do Brasil na torsão machadiana", superpondo, na leitura de "Um homem célebre," dois planos de análise. Num primeiro plano, a formação da literatura brasileira, formulada por Antonio Candido com agudo senso sociológico e histórico, reveste o entrecho do conto machadiano de um sentido especial, já que o lapso entre a vocação polquista e o ideal clássico do célebre Pestana do conto marca um desarranjo estrutural, em que se desenrola uma experiência literária que é também, a seu modo, a de Machado de Assis. Machado, entretanto, como sugere o artigo, teria realizado uma síntese que o famoso pianista mal esboça, e mal pode esboçar, porque vive afinal no constante dilema entre os pólos irreconciliáveis da referência local e da idéia forânea, oscilando entre o progresso legitimado pela consciência ilustrada e o conteúdo regressivo, mas não menos legítimo, do chamado local, com seus toques supostamente africanos e com a força das ruas. Num segundo plano, a idéia de "torsão" 
vem em auxílio da compreensão dos momentos de "fratura" do personagem principal, entre fascinado e perturbado por aquilo mesmo que ele é capaz de produzir (a polca que lhe sai límpida e lépida) e por aquilo também que revela sua própria incapacidade (a música erudita que lhe escapa todo o tempo, já que o império das ruas e dos salões é mais forte que o recato clássico que ele busca em vão). Neste segundo plano de interpretação, somos levados a perceber que o sujeito do conto é incapaz de gozar sua própria produtividade, e que, afinal, é nos equívocos e na superfície (ou no caráter superficial) de seus atos criadores que se desenrolam os seus mais fundos desejos (um deslizamento constante entre o fundo e o raso, que a banda de Moebius, de lacaniana memória, ajuda a visualizar). Este último artigo é uma mostra clara do caráter produtivo do encontro entre questões usualmente tratadas no campo dos estudos literários, como a formação e o comportamento da voz narrativa, e questões menos freqüentadas, como aquelas que, interrogando a oscilação do sujeito, tocam simultaneamente a literatura e a psicanálise.

Por fim, na seção de resenhas são comentados cinco livros recentes, que muito acrescentam a fortuna crítica machadiana: quatro estudos publicados ao longo do último ano, e uma obra - The Author as Plagiarist - que, publicada em 2006, é hoje o mais importante levantamento crítico sobre Machado de Assis em uma língua estrangeira.

Uma última observação, sobre algo que me parece o maior e talvez mais curioso equívoco a cercar a obra machadiana, e que terá se tornado mais evidente neste efusivo ano de comemorações. É que, como vários dos artigos aqui reunidos ressaltam, há em Machado um tom abertamente pessimista, que vai da mais funda melancolia ao simples desdém pela criatura humana. Até aqui, o leitor judicioso não terá visto nada de novo. Mas, bem ajustadas as lentes (e Machado sabia que isso de enxergar mal tem em geral a ver com as lentes), há algo de contraditório no movimento que tenta converter Machado de Assis em uma estátua impoluta. Ademais, não é incomum imaginá-lo como o escritor que proveria a revanche da "nossa" situação periférica, isto é, o autor que finalmente permitiria que a literatura brasileira se ombreasse a outras, mais prestigiosas. Como nota final, gostaria de sugerir que a obra de Machado resiste porventura, surdamente, ao bem-intencionado desejo de convertê-la em vetor edificante da cultura brasileira. Pouco ou nada há de edificante em Machado de Assis. Conquanto justas, as homenagens que lhe prestamos guardarão sempre essa sensação final de que, erguido o edifício, ele vai esboroar-se em seguida, no momento mesmo em que tentamos segurá-lo. Talvez, então, o desafio seja compreender a transitoriedade, mais que a estabilidade, dessa literatura que a todos fascina.

Princeton, NJ, novembro de 2008. 